\title{
As práticas discursivas da Administração de Empresas: análises sobre a dominação do trabalho e do trabalhador
}

\author{
Flávia Manuella Uchôa de Oliveira ${ }^{1}$ \\ Universidade de São Paulo (São Paulo, SP, Brasil)
}

\begin{abstract}
Neste artigo apresentamos uma análise de práticas discursivas e de uma lógica administrativa que vigora nas empresas. Por empresa entendemos toda organização constituída para explorar determinado ramo de negócio no mercado dentro do sistema capitalista. É nosso objetivo caracterizar os usos da Administração como campo de conhecimento e de formação de profissionais para resoluções dos problemas sobre o trabalho que a modernidade fez emergir. Utilizando-nos da leitura de Michel Foucault, pois encontramos suporte em suas análises sobre a história e a funcionalidade do poder. Procedemos com a análise documental de ementas e de referências bibliográficas indicadas nas disciplinas de dois cursos de duas instituições brasileiras: a Escola de Administração de Empresas de São Paulo da Fundação Getulio Vargas (Eaesp-FGV) e o curso de Administração da Faculdade de Economia, Administração e Contabilidade da Universidade de São Paulo (FEA-USP). Diante deste exame, pudemos formular algumas reflexões como resultado: a Administração de Empresas é a ciência da demonstração, o que se faz produtivo da realidade ou o que se produz nela é o que se torna científico.
\end{abstract}

Palavras-chave: Psicologia Social do Trabalho, Poder, Disciplina, Controle, Administração de Empresas.

This paper aims to analyze the discursive practices and the administrative logic that are valid in companies. We understand company as every organization constituted to explore certain business in the market within the capitalist system. It is our objective to characterize the uses of Business Administration as a field of knowledge and training of professionals to solve the problems that modernity has created to work and its work force. To do it so, we used Michel Foucault's analysis of history and functionality of power. We proceeded with documentary analysis of menus and bibliographical references indicated in the subjects of two courses of two Brazilian institutions: the School of Business Administration of São Paulo of the Getulio Vargas Foundation (Eaesp-FGV) and the Business Administration course of the Faculty of Economics, Administration and Accounting of the University of São Paulo (FEA-USP). After this exam, we could formulate some reflections as results: Business Administration is the science of demonstration; that which is product of a practice in reality or is produced in it becomes scientific.

Keywords: Social Psychology, Work Psychology, Work, Power, Discipline, Control, Business Administration.

\section{Introdução}

$\mathrm{N}$ este artigo apresentamos uma análise da constituição de práticas discursivas e de uma lógica administrativa que vigoram nas empresas². Esta análise é parte do estudo desenvolvido durante o mestrado da autora ${ }^{3}$.

1 Doutoranda pelo Programa de Pós-Graduação em Psicologia Social do Instituto de Psicologia da Universidade de São Paulo.

2 Por empresa entendemos uma organização constituída para explorar determinado ramo de negócio no mercado, dentro do sistema capitalista. Tal lugar possui uma preponderância na organização do trabalho no capitalismo tardio. A ideia da empresa capitalista como espaço, tempo e discurso sobre a gestão do trabalho e do trabalhador se impõe como uma das principais formas de organização da vida econômica e social. Mesmo na América Latina, com expressivo número de $48 \%$ de trabalhadores informais (Tokman, 2011 apud Stecher, 2015), as organizações empresariais representam um papel central na produtividade e na geração de empregos assalariados. Não descartamos os recorrentes momentos de tensão e de flexibilização das garantias sociais do emprego, nem de outras formas de organização do trabalho. Mas, de forma geral, indicamos uma supremacia da ideia da empresa capitalista e das relações nela estabelecidas para a gestão do trabalho.

3 A pesquisa de mestrado em questão (Oliveira, 2016) foi desenvolvida ao longo dos anos de 2014 e 2015, e defendida em fevereiro de 2016, no Programa de Pós-graduação em Psicologia Social do Instituto de Psicologia da Universidade de São Paulo, com a orientação da Professora Dra. Leny Sato. 
É nosso objetivo caracterizar os usos da Administração de Empresas como campo de conhecimento e de formação de profissionais para resoluções dos problemas que a modernidade e, em específico, o mundo do trabalho a partir da modernidade, fez emergir. Ao utilizarmos a palavra "lógica", portanto, tratamos deste caminho do pensamento construído pela Administração sobre o trabalho. Analisá-lo e caracterizá-lo são as principais tarefas colocadas para esta investigação.

Compreendemos a empresa como um modo de subjetivação e consideramos importante analisar quais as verdades que estamos compelidos a produzir para nos tornarmos sujeitos. $\mathrm{O}$ caráter dispersivo e modular que se instaura na sociedade contemporânea possibilita uma ampliação da ideia da empresa e de sua relação com o mundo social. Estudar, descrever e compreender este lugar nos parece uma possibilidade de aprofundamento crítico que fortalece o conhecimento das relações de trabalho e podem afetar diretamente políticas e práticas de gestão. Entendemos que nosso trabalho pode ser associado a pesquisas anteriores sobre a empresa, principalmente na Psicologia Social do Trabalho, fomentando e ampliando a discussão do tema (Bernardo, 2006; Farina, 2015; Barros, 2010, 2015; Pereira, 2015; Stecher, 2015).

Utilizando-nos da leitura de Michel Foucault (1985a, 1985b, 1988, 1999a, 1999b, 2003, 2010) e de alguns comentadores de sua obra (Eribon, 1996; Deleuze, 2005; Gutting, 2005), buscando um aporte teórico em suas análises sobre a história e a funcionalidade do poder. Partimos de algumas premissas: a primeira delas seria relativa à compreensão de que nomear os objetos de estudo é localizá-los em uma relação de descrição, mas antes, e principalmente, da criação deste mesmo objeto. Também compreendemos que o estudo dos sujeitos produz sujeitos e atualiza a noção de sujeito na "ordem" social, em estratos históricos específicos. Desta maneira, o estudo da divisão e organização do trabalho e dos trabalhadores pela Administração produziria em seus discursos e usos novas formas de trabalhar e de ser trabalhador.

Este campo de conhecimento sobre o trabalho em sua constituição fabrica um saber de uso político e estratégico. A emergência da Administração de Empresas e da formação de profissionais para sua aplicação é dado no contorno de padrões e normalizações que possibilitaram o governo dos sujeitos, o controle de suas existências no trabalho e para o trabalho. Estes padrões e ferramentas administrativos existiriam, portanto, para o controle dos corpos e serviriam como tecnologias do poder e, por isso mesmo, como fundamentos para uma "sujeitificação". A ciência administrativa se desenvolve, neste sentido, para a compreensão e a imposição produtivas das regularidades dos indivíduos no intuito de melhor governá-los no trabalho. Persistir na descrição destas tecnologias constitui as bases deste estudo.

\section{O caráter disciplinador do discurso científico}

Pensamos ser necessário, de antemão, apontar com mais ênfase o caráter disciplinador do discurso das ciências, estudado por Michel Foucault (1985a, 1985b, 1999a), para assim prosseguirmos com o método e a análise do material abordado neste breve estudo.

Neste sentido, o discurso não é somente um meio de luta, antes é objeto desta luta: "Por mais que o discurso seja aparentemente bem pouca coisa, as interdições que o atingem revelam logo, rapidamente, sua ligação com o desejo e o poder" (Foucault, 1999a, p. 10). O poder de nomear, classificar, estabelecer, determinar por meio do discurso é o objeto de uma luta que se trava pelo poder, no poder. Em toda sociedade, haveria uma produção do discurso que está, ao mesmo tempo, "controlada, selecionada, organizada e redistribuída" em um determinado número de processos que tem por papel localizar seus poderes e perigos e 
"dominar seu acontecimento aleatório, esquivar sua pesada e temível materialidade" (Foucault, 1999a, p. 8).

É por volta do século XVI e XVII, na Inglaterra, especialmente com a filosofia iluminista, que emerge a vontade de saber fundamentada na averiguação, na prova e na técnica. O sujeito que conhece não pauta seu conhecimento na leitura mas na verificação; não mais no comentar, e sim no constatar. Tal vontade de saber institucionalizou-se, distribuiu os saberes e os repartiu em um sistema educacional, escolar e pedagógico. A vontade de saber, institucionalizada e distribuída, exerce uma coerção aos demais discursos; há nisto a separação e a determinação entre o que seria um discurso verdadeiro e um discurso falso.

É notável que na sociedade ocidental houve o desenvolvimento de discursos de verdade requeridos por um incessante escrutínio do verdadeiro em detrimento do dito falso. Foucault aponta isto em análise sobre o direito e a economia, por exemplo:

[...] as práticas econômicas, codificadas como preceitos ou receitas, eventualmente como moral, procuraram, desde o século XVI, fundamentar-se, racionalizar-se e justificar-se a partir de uma teoria das riquezas e da produção; penso ainda na maneira, como um conjunto tão prescritivo quanto o sistema penal procurou seus suportes e sua justificação, primeiro, é certo, em uma teoria do direito, depois, a partir do século XIX, em um saber sociológico, psicológico, médico, psiquiátrico: como se a própria palavra da lei não pudesse mais ser autorizada, em nossa sociedade, senão por um discurso de verdade (Foucault, 1999a, p. 19).

Uma disciplina, no entanto, não é o conjunto sistematizado de discursos verdadeiros sobre determinado objeto de estudo; também não são os discursos aceitos sobre determinado fenômeno. As disciplinas são feitas tanto de verdades quanto de erros. Há, no entrelace destes conhecimentos, uma eficácia histórica; há condições a serem atingidas para que determinados pressupostos sejam tomados como partes das disciplinas. A questão passa a ser a localização das preposições dentro de um verdadeiro: "É sempre possível dizer o verdadeiro dentro de uma exterioridade selvagem; mas não nos encontramos no verdadeiro senão obedecendo as regras de uma 'polícia' discursiva que devemos reativar em cada um de nossos discursos" (Foucault, 1999a, p. 35).

A disciplina é, portanto, uma economia dos discursos, controlando-os em sua distribuição e redistribuição no jogo entre o verdadeiro e o falso. A multiplicidade de comentários e a propagação destes deve ser relacionada não somente à infinidade da criação dos discursos, em seu caráter positivo, mas também à coerção e à restrição em que funcionam. As disciplinas e todo o sistema educacional derivado delas é uma forma política de conservar ou transformar a apropriação dos discursos, bem como dos saberes e dos poderes que estes trazem consigo.

Seria importante localizar o que é a ciência na economia dos jogos discursivos sobre o trabalho. Propor uma análise não apenas do que seria a ciência mas de sua construção como campo de poder, de poder saber e proferir seu saber; de construção de meios para a divulgação dos saberes (instituições, técnicas, laboratórios, experimentos) e para a intervenção destes saberes na atualização da "ordem" social. Propõe-se, dessa maneira, pensar a Administração de Empresas como fonte específica de poder saber e proferir o conhecimento sobre o trabalho e o trabalhador, atualizando e reproduzindo as formas de trabalhar e de ser trabalhador amparados em ciências.

\section{Material e método}

Para efetivar esta proposta, empreendemos um estudo qualitativo instrumentalizado pela análise documental. Encaminhamos a discussão da construção dos campos de 
conhecimento e de atuação da Administração de Empresas como ciência formal que constitui um lugar determinado para saber e para poder dizer sobre este saber, o trabalho. Mediante a construção deste campo de conhecimento científico como disciplina organizada em um sistema educacional tão amplo, foi necessário concentrar nosso exame especificamente na caracterização de discursos desta disciplina e de seus profissionais no Brasil.

Como ter acesso e contato com estes campos de produção teórica e de formação profissional foi a pergunta que guiou a construção de nosso método. Primeiramente, buscamos as instituições que produzem, reproduzem e conduzem a formação e divulgação do conhecimento em Administração no país. Decidimos por entender a função administrativa nos cursos de graduação de Administração de Empresas pelo protagonismo desta função nas empresas.

Diante do amplo número de cursos de Administração no Brasil ${ }^{4}$, a escolha das que seriam investigadas deu-se pelo reconhecimento do prestígio das escolas como as principais formadoras de administradores. Por meio destes requisitos, selecionamos a Escola de Administração de Empresas de São Paulo da Fundação Getulio Vargas (Eaesp-FGV) e o curso de Administração da Faculdade de Economia, Administração e Contabilidade da Universidade de São Paulo (FEA-USP). O prestígio das duas faculdades dá-se tanto em nível de graduação, haja vista a história de pioneirismo e tempo de existência dos cursos (meados dos anos de 1950), o índice de concorrência em seus vestibulares, como também pelo reconhecimento em nível de pós-graduação no Brasil que já foi discutido e indicado em estudos anteriores (Guimarães et al., 2009; Castro, 1981), e que também está associado ao conceito dos programas na Coordenação de Aperfeiçoamento de Pessoal de Nível Superior (Capes).

Para estruturar os fundamentos desta análise, partimos da seleção das disciplinas oferecidas e do exame de suas ementas nos cursos de graduação das duas escolas acima citadas. Buscamos dentre todas as disciplinas listadas em ambas as graduações aquelas que: 1) intitulavam uma introdução à Administração e a seus principais conceitos; 2) anunciavam o estudo das ferramentas de gestão de pessoas, e também as que utilizavam definições da Psicologia para explicar o comportamento organizacional ou as relações no trabalho em suas ementas. Buscamos entender a lógica administrativa em seus processos e em seus "recursos humanos". Foram identificadas oito disciplinas ${ }^{5}$ nos dois cursos analisados com ampla referência bibliográfica, perfazendo um total de 147 textos indicados. Sendo 128 textos indicados como bibliografia em cinco disciplinas na Eaesp-FGV e 19 indicados em três disciplinas na FEA-USP.

Decidimos estudar as ementas ${ }^{6}$ das oito disciplinas e analisá-las em suas referências de leituras por serem registros institucionais. As ementas possuem um caráter de apresentação, de roteiro e de predefinições. Elas estabelecem os objetivos e conteúdos que fundamentam e que serão estudados e estimulados durante a formação. Dessa maneira, encontramos neste material uma possibilidade de contato com a formação do administrador, ou, de outra forma, com os principais discursos científicos que são produzidos e reproduzidos na graduação dos futuros administradores.

\footnotetext{
4 Segundo o Censo da Educação Superior do INEP (Instituto Nacional de Estudos e Pesquisas Educacionais Anísio Teixeira) divulgado em 2015, o número de cursos de Administração de Empresas no Brasil é de 2.107. Para mais informações sobre o Censo: http://portal.inep.gov.br/web/censo-da-educacao-superior.

5 Cabe ressaltar que algumas disciplinas da FEA-USP como "Introdução à Psicologia" são oferecidas pelo Instituto de Psicologia e não são listadas entre as disciplinas oferecidas na Faculdade de Administração. Ainda sobre essa faculdade, é importante sublinhar que outras disciplinas como "Tópicos em Administração Geral” I e II possuem o caráter introdutório e poderiam ser consideradas na análise aqui proposta, mas nas informações expostas no sistema online não há indicação de bibliografia, apenas ementa. Dessa forma, não poderiam ser utilizadas nos critérios estabelecidos para a análise.

6 No sistema de informações públicas disponibilizado pela FEA-USP, não é dado o nome "ementa" às informações sobre as disciplinas. Apenas são elencados, de forma geral, "objetivos" do curso. No entanto, aqui, decidiu-se tratar estes "objetivos" como as ementas das disciplinas.
} 
Criamos dois quadros correspondentes às duas universidades citadas, com o intuito de facilitar a leitura e a análise dos dados (Quadros 1 e 2).

Quadro 1: Disciplinas selecionadas da Escola de Administração de Empresas de São Paulo da Fundação Getulio Vargas (Eaesp-FGV) e suas respectivas ementas

\begin{tabular}{|l|l|}
\hline Nome da Disciplina & Ementa \\
\hline Introdução à Administração & $\begin{array}{l}\text { "O curso apresenta as principais funções do administrador e a evolução das teorias } \\
\text { administrativas, de modo a formar um quadro de referências que possa ser utilizado } \\
\text { para análise das práticas e desafios presentes nas organizações" }\end{array}$ \\
\hline Administração de Pessoal & $\begin{array}{l}\text { "A disciplina tem como objetivo analisar elementos centrais da Gestão Estratégica } \\
\text { de Pessoas, buscando identificar as formas por meio das quais ela produz resultados e } \\
\text { adiciona valor. Serão discutidos e analisados papéis, responsabilidades e ferramentas } \\
\text { de gestão no contexto de transformação acelerada do ambiente organizacional" }\end{array}$ \\
\hline Teoria das Organizações & $\begin{array}{l}\text { "Analisar as organizações enquanto construção social e psíquica, onde o poder } \\
\text { utiliza mecanismos que atuam diretamente no imaginário dos indivíduos" }\end{array}$ \\
\hline Psicologia I & $\begin{array}{l}\text { "Propiciar ao aluno o reconhecimento da dimensão psicológica nas relações } \\
\text { humanas e articulá-las ao trabalho. Fornecer subsídios para uma reflexão crítica do } \\
\text { constante interjogo entre o individual e o grupal, permeado pela peculiaridade do } \\
\text { contexto" }\end{array}$ \\
\hline Psicologia II & $\begin{array}{l}\text { "O curso propõe o estudo do comportamento dos indivíduos nas organizações, para } \\
\text { que o aluno possa perceber o papel do fator humano no desempenho das tarefas, na } \\
\text { produtividade, no binômio satisfação/insatisfação no trabalho, identificando, assim, } \\
\text { algumas variáveis que constroem a dinâmica organizacional" }\end{array}$ \\
\hline
\end{tabular}

Quadro 2: Disciplinas selecionadas da Faculdade de Economia, Administração e Contabilidade da Universidade de São Paulo (FEA-USP) e suas respectivas ementas

\begin{tabular}{|l|l|}
\hline Nome da Disciplina & Ementa \\
\hline Fundamentos de Administração & $\begin{array}{l}\text { "- Apresentar ao aluno o conceito de organização e sua relação com o processo } \\
\text { administrativo } \\
\text { - Apresentar ao aluno uma primeira noção do processo administrativo e suas } \\
\text { funções } \\
\text { - Descrever as principais contribuições teóricas e práticas para a formação do } \\
\text { conhecimento administrativo." }\end{array}$ \\
\hline Gestão de Pessoas & $\begin{array}{l}\text { "- Assimilar os principais pressupostos teóricos que fundamentam a definição de } \\
\text { políticas e práticas de Gestão de Pessoas nas Empresas } \\
\text { - Conhecer as principais atividades e procedimentos dos vários subsistemas da } \\
\text { Administração de Pessoas e os impactos de sua operacionalização em diferentes } \\
\text { instâncias organizacionais } \\
\text { - Familiarizar-se com processo de formulação de Políticas de Gestão de Pessoas, } \\
\text { identificando seus elementos componentes para implementação e avaliação." }\end{array}$ \\
\hline Comportamento Organizacional & $\begin{array}{l}\text { "Desenvolver nos alunos a sensibilidade para compreender as relações que se } \\
\text { estabelecem no interior das organizações entre indivíduos e grupos/organização e } \\
\text { conhecer os fatores determinantes de como as referidas relações acontecem na } \\
\text { dinâmica organizacional." }\end{array}$ \\
\hline
\end{tabular}

De início, ressaltamos que a estrutura das ementas em ambas as universidades é bastante distinta. As ementas encontradas da Eaesp-FGV são colocadas em um único documento que explica todos os semestres e disciplinas da graduação disponibilizado no site da Escola. As referências indicadas nas ementas da FGV são amplas tanto em número - algumas disciplinas têm por referência mais de 30 textos e livros para serem estudados em um semestre -, quanto na diversidade de temas abordados incluindo textos de filosofia e sociologia que poderiam ser alocadas em vários outros cursos de graduação. 
Por sua vez, as ementas da FEA-USP podem ser acessadas no espaço de interação pública do sistema Júpiter (sistema de suporte online para graduação que disponibiliza notas, requerimento e status de matrícula, disciplinas cursadas etc.), individualmente, pelos nomes das disciplinas. Nestas ementas, o número de indicações bibliográficas é extremamente reduzido, se comparado às indicações da Eaesp-FGV. As referências parecem concentrar o foco das leituras na administração e em suas ferramentas, sem a inclusão de textos filosóficos ou sociológicos.

No sistema da FEA-USP ainda se pode encontrar o "programa reduzido" de cada disciplina com os principais assuntos a serem tratados. As referências indicadas nas três disciplinas desta faculdade são mais centradas nas técnicas da administração (ferramentas, conceitos, fundamentos administrativos). Há de se apontar que todas as ementas analisadas em ambas as faculdades aparentam não ser atualizadas com frequência; não há registro da atualização da ementa em nenhuma das universidades. Há, contudo, apenas na USP, a data de ativação da disciplina no curso.

Deve ser sinalizado também que o foco desta tentativa de análise não está posto em termos da história destas instituições de ensino, nem nas especificidades da formação do administrador no Brasil. Reconhece-se, contudo, que a história destas instituições corresponde a uma importação iniciada na década de 1950 da Administração americana. Além disto, caberia ressaltar que aspectos específicos da formação e publicação na Administração no Brasil são discutidos e apontam para a ideia do trabalho do administrador voltado à "grande empresa", conforme estudos anteriores (Bertero, Caldas, \& Wood Jr., 1999; Motta, 1983; Manzini-Covre, 1981). No entanto, lembramos que o foco de nossa análise é situar as regularidades do discurso pautado nas ciências que permeiam a formação do administrador.

Pela amplitude de indicações bibliográficas, com mais de 100 livros indicados para a leitura, decidimos como forma de trabalho, buscar nestas referências os seguintes conteúdos: a) textos, entre livros e artigos, que estivessem indicados em mais de uma disciplina, dentre as oito selecionadas; b) manuais de introdução à disciplina escritos preferencialmente por administradores; c) e, caso houvesse, relato de prática em empresas ou estudo de caso, em cada uma das oito disciplinas analisadas. Preferimos optar por textos de pensadores da Administração no intuito de ter o contato mais próximo possível com o discurso "integralmente" administrativo. Por meio destas definições, listamos em ordem alfabética as referências que foram lidas para a análise e dispusemos no Quadro 3.

No intuito de situar as perguntas que fazemos a estas ementas e textos, devemos compreender a busca por fundamentos que anunciam os objetivos da formação destas disciplinas e, especialmente, de seu entrelace nas práticas empresariais, bem como suas principais configurações para a atuação profissional na temática do trabalho. Foi possível lançarmos algumas questões para a reflexão, para possíveis respostas e para outras novas questões que são procuradas nos textos: O que é "administrar" empresas? Por que "administrar" o trabalho amparado em "cientificidades"? Por que aplicar ao trabalho "administrado" teorias psicológicas ou mesmo sociológicas e filosóficas? 


\section{Quadro 3: Lista de referências}

1. Arruda, M. C. C. et al. (2001). Fundamentos de ética empresarial e econômica. São Paulo: Atlas.

2. Bateman, T., \& Snell, S. (1998). Administração: construindo vantagem competitiva. São Paulo: Atlas.

3. Bresser-Pereira, L. C., \& Motta, F. C. P. (1998). Introdução à organização burocrática (6- ${ }^{\underline{a}}$ ed.). São Paulo: Brasiliense.

4. Brown, M. T. (1993). Ética nos negócios. São Paulo: Makron Books.

5. Chiavenatto, I. (1999). Gestão de pessoas: o novo papel de recursos humanos. São Paulo: Campos.

6. Dutra, J. S. (2002). Gestão de pessoas: modelos, processos, tendências e perspectivas. São Paulo: Atlas.

7. Eboli, M. (Org.) (1999). Universidades corporativas: educação para as empresas do século XXI. São Paulo: Schukler.

8. Etzioni, A. (1989). Organizações modernas (8ª ed.). São Paulo: Pioneira.

9. Fayol, H. (1987). Administração industrial e geral (9ª ed.). São Paulo: Atlas.

10. Ferreira, A. A. et al. (1997). Gestão empresarial. São Paulo: Pioneira.

11. Flannery, T. P., Hofrichter, D. A., \& Platten, P.E. (1997). Pessoas, desempenho e salários: as mudanças na forma de remuneração nas empresas. São Paulo: Futura.

12. Fleury, A., \& Fleury, M. T. L. (2000). Estratégias empresariais e formação de competências: um quebra-cabeça caleidoscópico da indústria brasileira. São Paulo: Atlas.

13. Fleury, M. T. L., \& Fischer, R. M. (1992). Relações de trabalho e políticas de gestão: uma história das questões atuais. Revista de Administração da USP, 27 (4), 5-15.

14. Fischer, A. L. (2002). Um resgate conceitual e histórico dos modelos de gestão de pessoas (pp. 11-34). In M. T. L. Fleury (Org.), As pessoas na organização. São Paulo: Gente.

15. Grove, A. (1995). Administração de alta performance. São Paulo: Futura.

16. Homans, G. C. (1967). As pesquisas na Western Electric (pp. 5-34). In Y. Balcão, \& L. Cordeiro (Orgs.), O comportamento humano na empresa: uma antologia. Rio de Janeiro: FGV.

17. Katz, D., \& Kahn, R. L. (1987). Psicologia social das organizações (3a ed.). São Paulo: Atlas.

18. Maximiano, A. C. A. (2000). Introdução à administração (5ª ed.). São Paulo: Atlas.

19. Milkovich, G. T., \& Boudreau, J. W. (2000). Administração de recursos humanos. São Paulo: Atlas.

20. Mintzberg, H. (1995). Criando organizações eficazes. São Paulo: Atlas.

21. Motta, P. R. (1990). Gestão contemporânea: a ciência e a arte de ser dirigente. Rio de Janeiro: Record.

22. Nadler, D. A., Hackaman, Jr., \& Lawler, E. (1983). Comportamento organizacional. Rio de Janeiro: Campus.

23. Ohno, T. (1988). Toyota production system: beyond large scale production. Portland, Oregon: Productivity Press.

24. O'Reilly, C. A, \& Pfeffer, J. (2001). Talentos ocultos: como as melhores empresas obtêm resultados extraordinários com pessoas comuns. Rio de Janeiro: Campus.

25. Simon, H. A. (1979). Comportamento administrativo: estudo dos processos decisórios nas organizações administrativas. Rio de Janeiro: FGV.

26. Stoner, J. A. F., \& Freeman, R. E. (1995). Administração (5ª ed.). Rio de Janeiro: Prentice Hall do Brasil.

27. Taylor, F. W. (1987). Princípios da administração científica (7ª ed.). São Paulo: Atlas.

28. Thompson, V. A. (1967). Moderna organização. Rio de Janeiro: USAID.

29. Ulrich, D. (2000). Os campeões de recursos humanos. São Paulo: Futura.

30. Womack, J., Jones, D. T., \& Roos, D. (1992). A máquina que mudou o mundo. Rio de Janeiro: Campus.

\section{Os registros encontrados e as ideias que deles emergem}

Pela escolha de trabalho com apenas dois cursos de graduação, não se pode afirmar que o que é anunciado nas ementas é de correspondência com as realidades dos cursos ou das instituições. O modo de preencher as ementas e de indicar referências não é o cerne da discussão aqui proposta. Ressaltamos também que algumas obras dentre as lidas tornaram-se ilustrativas para a análise e não poderíamos deixar de citá-las literalmente. Os textos clássicos representados por Fayol, Taylor, Ford e Ohno, por exemplo - foram amplamente utilizados pois 
sustentam práticas ainda atuais e nos fornecem pistas de uma história que é feita de costuras, muito mais do que de rupturas de pensamentos.

Optamos por, na maioria de nossas análises, exemplificar a discussão por meio destes textos clássicos para demonstrar sua longevidade na história da administração e, para além disto, fornecer ilustrações desta "costura" de técnicas que se fortalecem em reciprocidade. Para que compreendamos o que nomeamos "costura", recorremos às afirmações de Stoner e Freeman (1995). No manual de administração, intitulado "Administração", esses pesquisadores americanos apresentam não somente as teorias da administração moderna, mas buscam, por temas, especializar o pensamento administrativo elaborando prescrições sobre a estrutura organizacional, sobre liderança e controle nas organizações.

No entanto, apontam de saída que as soluções teóricas da administração ainda estariam por vir, ou melhor, poderiam jamais ser encontradas. Os administradores teriam de continuamente selecionar sozinhos a melhor solução para dada situação. Ao falarem das escolas mais recentes do pensamento administrativo, do final do século XX, eles afirmam:

Eventualmente, essas perspectivas mais recentes podem levar à integração das escolas clássica, comportamental e quantitativa; mas, por outro lado, alguma nova abordagem, que ainda não surgiu no horizonte, pode realizar esse objetivo. Também é possível que jamais ocorra essa esperada solução teórica, e que os administradores tenham de continuar a selecionar sozinhos a perspectiva ou as perspectivas apropriadas a determinada situação [grifos nossos] (Stoner, \& Freeman, 1995, p. 37).

Identificamos, dessa maneira, que os textos clássicos são encontrados nos manuais recentes da administração não só para "contar uma história" do pensamento administrativo, mas para serem possíveis aplicações na rotina do administrador em recortes que são feitos a partir das necessidades de cada situação. As técnicas e prescrições iniciadas no início do século XX são formulações que ainda vigoram na prática administrativa atual de acordo com a conveniência de sua utilização. Não foram ultrapassadas, mas se integram em costuras para a eficiência da dominação do trabalho e do trabalhador.

\section{Análises}

\section{A tensão e a ambiguidade necessárias à função administrativa}

É notável que, nas ementas e nas indicações de leitura referidas nas disciplinas das duas faculdades, há uma repetição sobre os fundamentos que parecem permear qualquer teoria na função administrativa. Como referido na ementa da Eaesp-FGV, na disciplina "Introdução à Administração": "O curso apresenta as principais funções do administrador e a evolução das teorias administrativas, de modo a formar um quadro de referências que possa ser utilizado para análise das práticas e desafios presentes nas organizações [grifos nossos]".

É necessário que se apresente o que é administrar cientificamente em forma de ato; em ações estabelecidas que embasem a cientificidade. Para tanto, como é indicado por Jules Henri Fayol - engenheiro francês e teórico da administração, fundador da Teoria Clássica da Administração - em seu livro "Administração industrial e geral":

Administrar é prever, organizar, comandar, coordenar e controlar. Prever é perscrutar o futuro e traçar o programa de ação. Organizar é constituir o duplo organismo, material e social, da empresa. Comandar é dirigir o pessoal. Coordenar é ligar, unir e harmonizar todos os atos e todos os reforços. Controlar é velar para que tudo corra de acordo com as regras estabelecidas e as ordens dadas (Fayol, 1916/1976, p. 17). 
São apresentados os fundamentos de uma ação; são os verbos que fundamentam primordialmente a administração. Não haveria teoria estritamente administrativa que não venha da experimentação destes fundamentos no próprio trabalho, no próprio trabalhador: é a criação do trabalhador-administrador. É na experiência de administrar que se cria o administrador (e sua funcionalidade): "A administração, que comporta a aplicação de inúmeros conhecimentos e de muitas qualidades pessoais, é sobretudo a arte de lidar com os homens; e nessa arte, como em muitas outras, é forjando que se faz o forjador" [grifos nossos] (Fayol, 1016/1976, p. 136).

O caminho percorrido é do fazer ao controlar, e do controlar para se fazer mais e com mais eficiência: "A prática compreende as soluções criadas no mundo das organizações reais. A teoria compreende os conhecimentos abstraídos dessa prática e sistematizados" (Maximiano, 2000, p. 29). Há na Administração o recurso de se nomear "arte" o sentido da profissão de administrador. A arte como definição é múltipla e serve historicamente para determinar exclusões e inclusões em uma economia discursiva, trata-se de um conceito flutuante na história ${ }^{7}$ Serviria, desse modo, a uma mutável definição do que é administrar, ao mesmo tempo que a estabelece e que a localiza em um lugar de importância "das artes". Esta autodenominação é a apropriação do poder no espaço e no tempo do que seja a "Arte", não importando se é "verdadeira" ou "falsa".

Maximiano (2000), em seu manual de introdução à disciplina intitulado "Introdução à Administração", expõe essa ambiguidade do pensamento administrativo em figura de uma constante mudança inserida em termos estabelecidos, em um "vai e vem" ininterrupto entre teoria e prática que designa um ciclo perpétuo, sem começo ou fim, sem vácuo ou sem porquês (Figura).

Figura: "Administração como corpo de conhecimento"

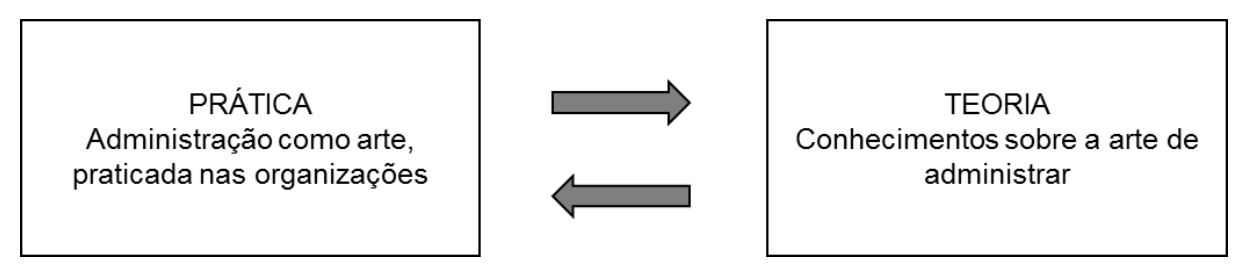

Fonte: Maximiano, 2000, p. 29.

O estudo de caso, o bechmarking e as "melhores práticas" - conforme exemplo da mudança ocorrida na indústria automobilística com o declínio da produção em massa e o desenvolvimento da produção enxuta, apresentada no livro "A máquina que mudou o mundo" (Womack,1992), indicado como referência em ambas as faculdades pesquisadas - não são à toa os métodos que imperam nas ciências administrativas por delimitarem este caminho do fazer ao controle do fazer em um ciclo sem intervalo possível. As práticas das empresas se tornam doutrinas da função administrativa.

As "muitas qualidades pessoais" que compõem esta "arte" também demonstram a necessária flexibilização (modulação) do que é requerido ao trabalhador. E isto pode ser exemplificado nas palavras de Bernardo (2009). Ao falar da entrada do termo "competência" na linguagem empresarial (nos moldes do toyotismo, mas não exclusivo dele), ela define o aprofundamento deste discurso flexível de valorização da pessoa do trabalhador que tem por

7 Podemos nos utilizar da breve explicação de João A. Frayze-Pereira (2005, p. 38) (ao relacionar a aproximação entre arte, psicologia e psicanálise) para demarcar a flutuação do conceito de Arte: "[...] após ter buscado saber o que é arte na Teoria da Arte, percebemos que o campo semântico do termo é, ele próprio, incerto. E que teóricos apontam como um dos aspectos da própria Arte as dificuldades que apresenta ao enquadramento numa definição fixa, positiva. Isto é, os teóricos encontram dificuldades para delimitar as fronteiras da própria Arte, pois, de um lado, a Arte não teve sempre, nem em toda parte, o mesmo estatuto, o mesmo conteúdo e a mesma função [...]". 
objetivo a promoção da individualização das relações de trabalho e a garantia de que também a subjetividade seja utilizada para os interesses da empresa. É a construção de uma propriedade instável que é validada dentro e fora do trabalho, em um exercício no qual o trabalhador deve "aprender a ser" mais do que "aprender a fazer".

Apesar da infinidade de práticas (modos de fazer), os eixos norteadores de qualquer atuação do administrador continuam a ser a organização, a previsão, a direção e a coordenação do trabalho e do trabalhador. As formas em que se dão estes verbos mudam em vocabulário, eles podem se sobrepor uns aos outros, estar em maior realce em determinada onda gerencial, no entanto, as raízes se mantêm. A atualização dá-se no vocabulário e nas ferramentas, apenas nas formas. O objetivo de exploração máxima do tempo de trabalho com o mínimo de recursos mantém-se intacto, ou melhor, mantém-se em crescente. Há, contudo, uma elasticidade que deve ser compreendida nestes fundamentos. Eles são apresentados como as bases da administração seja em Fayol (1916/1976), Taylor (1911/1990) ou Maximiano (2000).

Há de se doutrinar para o controle do trabalho, criar fundamentos que amparem a experiência de trabalhar. Ao mesmo tempo é somente da experiência da rotina de trabalho que se pode estabelecer os padrões deste controle. A administração tornada científica parece estar situada na tensão entre a rigidez do controle do trabalho e a volatilidade da experiência de trabalho. $\mathrm{O}$ administrador está na tensão de documentar o trabalho, mas não abusar desta documentação para o controle do trabalho.

O abuso de documentar o trabalho impediria o controle do trabalho em seus mais ínfimos aspectos. A rigidez deve ser fundamentada na fluidez da experiência. Parece ser esta impossibilidade de estabelecer bases firmes na fluidez que impulsiona as infinitas modas administrativas e gerenciais. É a documentação perene do controle para que não se perca o controle, mas para que se possa modificá-lo ao sabor das modas. Estas tensão e ambiguidade observadas nos fundamentos da administração podem ser encontradas de forma objetiva no livro de Henri Fayol, "Administração industrial e geral" (1916/1976), no qual o autor afirma que não poderá haver abuso da comunicação escrita na administração.

O autor afirma que sempre que possível a comunicação na administração deve ser verbal, recusando um "abuso da comunicação escrita", para a garantia de harmonia e de entendimento do que está sendo requerido ou ordenado. A relação verbal como fundamento das relações desimplicaria da função administrativa o registro e a documentação desta mesma relação na rotina. A escrita documenta e torna perene. Mas a função administrativa é variável, faz-se na difícil arte de medição em circunstâncias sempre diferentes, governando pessoas diferentes. $O$ não registro escrito passa a ser um princípio registrado na função administrativa: é preciso documentar que não se pode abusar da documentação das relações na administração.

É preciso disciplinar por regras tácitas, por convenções "livremente criadas". A "espontaneidade" da fabricação de regras e de se disciplinar nelas é parte do processo produtivo nas empresas e mantém um caráter de familiaridade emergente dos costumes deste ambiente específico. É uma familiaridade contratual que impõe a disciplina:

A disciplina consiste, essencialmente, na obediência, na assiduidade, na atividade, na presença e nos sinais exteriores de respeito demonstrados segundo as convenções estabelecidas entre a empresa e seus agentes. Essas convenções fixam as modalidades de disciplina, quer tenham origem em pactos livremente firmados ou aceitos sem uma discussão prévia, quer sejam escritos ou tácitos ou resultem da vontade das partes ou dos usos e costumes [grifos nossos] (Fayol, 1976, p. 36).

Esta criação "espontânea" de convenções parece também ser a função do grande número de conferências e reuniões nas organizações - reuniões de troca de turno, conferências de áreas específicas, encontros de lideranças -, a base de uma comunicação verbal. A comunicação verbal demarca o que deve ser feito, mas nem sempre documenta os meios para tais fins. A estratégia de uma relação pautada no verbal desfaz a impessoalidade da escrita, torna próximo aquele que deve obedecer e realizar as regras. Impõe a ele a prosódia. Regras 
ditas podem ser mais facilmente manejáveis, as escritas possuem uma formalidade que demora a ser desfeita neste incansável ciclo de impossibilidade e ambiguidade da função administrativa.

A clareza da regra escrita nem sempre favorece à arte de constante medição e avaliação do administrador:

Não existe nada rígido nem absoluto em matéria administrativa; tudo nela é uma questão de medida. Quase nunca se aplicará o mesmo princípio duas vezes em condições idênticas: é necessário ter em conta circunstâncias diversas e variáveis, homens igualmente variáveis e diferentes e muitos outros elementos também variáveis tais princípios serão, pois, maleáveis e suscetíveis de adaptar-se a todas as necessidades. A questão consiste em saber servir-se deles: essa é uma arte difícil que exige inteligência, experiência, decisão e comedimento [grifos nossos] (Fayol, 1976, p. 33).

Servir-se das situações, adaptar-se às necessidades e estar atento às variáveis e variações: é a sinuosa função de estar em vigilância. É a produção de ferramentas de vigilância, de tecnologias para a disciplina no trabalho e do trabalhador. Uma vigilância que se dá na produção, no produto e naquele que produz; uma vigilância que se dá na técnica: quais as melhores maneiras (mais eficientes e menos dispendiosas em recursos) de execução da atividade; dá-se no intelectual e na moral: quais os conhecimentos, "competências" e "habilidades" requeridas do trabalhador que favorecem a melhor execução da tarefa; dá-se no físico: atentar para a destreza e a saúde dos que exercem as funções, cuidar das ausências e presenças para tornar ainda mais rentável o processo produtivo.

Aqui se faz importante citarmos diretamente Foucault (2003) em sua análise sobre a vigilância nas fábricas. Ele afirma que neste cenário, das fábricas e empresas, se constitui um "novo tipo de vigilância". No capitalismo da modernidade, o controle não é somente exteriorizado na figura de um mestre, fala-se agora de "um controle intenso, contínuo" que está em paralelo ao longo do processo de trabalho. Não está localizado somente na produção, em seus recursos e instrumentos. Leva em conta, agora, "as atividades dos homens, seu conhecimento técnico, a maneira de fazê-lo, sua rapidez, seu zelo, seu comportamento". Vigiar torna-se uma função definida dentro do processo de produzir: "deve fazer parte integrante do processo de produção; deve duplicá-lo em todo o seu comprimento" [grifos nossos] (Foucault, 2003, p. 146).

\section{A duplicação da dominação}

Há, portanto, uma duplicação que se localiza no processo produtivo. Os homens são governados como recursos que se aplicam a determinada tarefa. Moldar estes homens em trabalhadores para a empresa é parte essencial da função administrativa. É a rotulagem não somente dos produtos, mas daqueles que produzem. O trabalhador é fabricado em sua função; é domesticado e disciplinado nos "usos e costumes" do mundo corporativo que ele adentra. É integrado à "família" da empresa, é sensibilizado em um novo vocabulário, em novas siglas. É treinado então a ser para produzir, reproduzir e produzir a si próprio. Isto pode ser exemplificado no que Fayol indica como um processo seletivo que considera elementos "pessoais" e não somente técnicos:

Verifica-se se o escolhido possui a dose necessária e capacidade técnica, mas, entre os candidatos de valor técnico quase equivalente, será dada a preferência ao que for considerado superior por suas qualidades de presença, autoridade, ordem, organização e outras, que são os próprios elementos da capacidade administrativa (1916/1976, p. 29).

O treinamento então duplica a vigilância sobre o trabalho. $O$ homem não é mais vigiado somente por fatores exteriores, mas agora é colocado como responsável por seu trabalho e por sua disciplina. Há de se constituir uma consciência para o trabalho. Taylor em seu livro "Princípios da administração científica" (1911/1990), ao falar da "vadiagem no trabalho", representa esta necessidade de disciplina não somente exterior, mas de uma consciência do 
trabalhador ao "pensar bem" em seu trabalho: "Não há dúvida de que a tendência do homem comum, em todos os atos de sua vida, é trabalhar devagar e comodamente, e só depois de pensar e observar bem a esse respeito, ou como resultado de exemplo, consciência ou pressão exterior, ele adota um ritmo mais rápido [grifos nossos]" (p. 30).

A produção, em sua técnica, em seus recursos não é o único aspecto a ser gerido. Gerir o trabalhador, o recurso humano, passa a ser o aspecto que protagoniza a função administrativa. É necessário induzir a uma convicção de pertencimento à empresa não somente contratual, mas para além desse vínculo. É necessário que esta indução seja feita no "verdadeiro", conforme lembra Frederik Taylor:

Portanto, para que haja alguma esperança de obter a iniciativa de seus trabalhadores, o administrador deve fornecer-lhes incentivo especial, além do que é dado comumente no ofício. Esse incentivo pode ser concedido de diferentes modos, como, por exemplo, promessa rápida de promoção ou melhoria; salários mais elevados, sob a forma de boa remuneração por peça produzida, ou por prêmio, ou por gratificação de qualquer espécie a trabalho perfeito e rápido; menores horas de trabalho, melhores condições de ambiente e serviço do que são dadas habitualmente etc., e, sobretudo, este incentivo especial deve ser acompanhado por consideração pessoal e amistoso tratamento que somente pode derivar de interesse verdadeiro, posto a serviço do bem-estar dos subordinados [grifos nossos] (1911/1990, p. 39).

E esta indução é parte crucial da arte de administrar: "Para que o pessoal seja estimulado a empregar no exercício de suas funções toda a boa vontade e o devotamento de que é capaz, é preciso que ele seja tratado com benevolência; e equidade resulta da combinação da benevolência com a justiça" (Fayol, 1916/1976, p. 53). A função do administrador também é duplicada em seu objetivo. $\mathrm{O}$ administrador é formado em uma íntima relação com o trabalho. Ele deve se fazer benevolente, sensível às necessidades dos trabalhadores, mostrar interesse "verdadeiro" por seus "colaboradores", ser um exemplo.

Assim como há a duplicação da vigilância que agora é feita não apenas no processo produtivo mas naquele que produz, há a duplicação da própria função administrativa. $\mathrm{O}$ trabalho do administrador, na figura do líder ou gerente, para tanto, se duplica na relação de si consigo e na relação com os que por ele são governados. $\mathrm{O}$ administrador é pois o vigilante duplo: o fiscal perpetuamente fiscalizado, utilizando as palavras de Foucault. Ele tem de se fazer administrador assim como tem de moldar aqueles que por ele são administrados: é o encontro do objeto forjado e do forjador. A relação que se impõe é duplicada, disciplinar-se e disciplinar.

Estas formas de duplicação se encadeiam. Ao nos apropriamos do vocabulário de Foucault, podemos refletir que não haveria possibilidade de recortar tais duplicações pois suas funções são interdependentes: uma duplicação só funciona em detrimento de outra, na hierarquia, de cima a baixo, mas também de baixo a cima, em diagonais e paralelas. Pois duplicar é também dobrar. Faz-se em uma formação de margens que vão de encontro em paralelo, que se curvam envolvendo e moldando. É como um repuxo no tecido, é a parte de dentro do relevo de um rótulo. É através destas duplicações que a lógica administrativa se expande por toda a empresa; antes colocada nos mais altos cargos da hierarquia, a lógica administrativa na atualidade parece estar implementada até nas "menores" funções dentro da organização. $\mathrm{O}$ administrador passa a ser qualquer um dentro dos muros da fábrica. Dessa forma, a lógica do administrador não é mais relacionada somente à hierarquia como Henri Fayol mencionou em 1916. Sem expiação e sem vácuo: a lógica administrativa escorreu para todos os cantos da empresa.

Por esta lógica, o modo de produzir e, por isso mesmo, de administrar esta produção determinaria o modo como vivemos. Isto é afirmado como parte da história da indústria. Tomemos como exemplo as palavras introdutórias de Womack sobre a mudança na produção (de uma produção em massa, caracteristicamente "fordista" para o modelo da produção "enxuta" caracteristicamente japonês) da indústria automobilística durante o século XX: 
Muitos de nós possuem um, alguns possuem mais de um e, ainda que não estejamos conscientes disso, tais automóveis, ônibus e caminhões desempenham importante papel em nossas vidas diárias. No entanto, a indústria automobilística é ainda mais importante para nós do que parece. Duas vezes neste século, ela alterou nossas noções mais fundamentais de como produzir bens. E a maneira como os produzimos determina, não somente como trabalhamos, mas ainda como pensamos, o que compramos e como vivemos (Womack, 1992, p. 1).

A lógica administrativa, dessa forma, também atravessa os muros da fábrica e tenta estabelecer as formas de viver e não somente de ser para trabalhar. Fayol (1916/1976) traz a preocupação da disseminação desta lógica nos primórdios da institucionalização da disciplina: "É necessário, pois, esforçar-se para inculcar as noções administrativas em todas as classes sociais" (p. 31). É esta coincidência que se pode apontar entre trabalhador e consumidor. Não haveria uma fronteira explícita entre produção e consumo. O modo de vida é consumado. A fábrica/empresa se multiplica em suas dominações, se pretende duplicada, está em vigilância interior e exterior. E para exercê-la há de utilizar da arte da administração e das demais disciplinas que possam a ela servir.

Neste sentido, cabe ainda ressaltar que há nesta lógica uma duplicação das demais disciplinas como suporte de um cientificismo. A lógica administrativa deve ser amparada por verdadeiros que a reforçam. Isto está posto na relação com a Psicologia como forma de dar conta do trabalhador, de sua seleção, integração e adaptação ao cargo; no entrelace com uma especialização da Medicina que deve cuidar do vigor e da saúde para o pleno exercício das atividades; na conexão com a Economia que tenta estabelecer as previsões de mercado, dos bolsões financeiros; no vínculo com o Direito, que rege contratualmente as relações estabelecidas dentro da empresa. Trata-se nesses pares, entre administração e outras disciplinas, da reativação dos discursos de verdade, da seleção dos verdadeiros em detrimento dos discursos ditos falsos.

\section{Comentários finais}

Tomamos aqui a "ciência" como demonstração entre saberes e práticas contextualizadas historicamente, rechaçando uma verdade-ritual de descobrimentos ou de revelações. No projeto teórico de Michel Foucault (1999b), no qual esta pesquisa está apoiada, propõe-se uma análise destas práticas discursivas da Administração, com um exame de enunciados que englobam esses saberes em uso. A tática (ou lógica) da função administrativa faz demonstrar e criar conceitos para o trabalho e para o trabalhador amparados em uma rede de saberes que se equilibram nas regularidades técnicas, dos corpos e de suas funções.

Ressaltamos que o discurso então produz sujeitos. Buscamos entender, assim exposto em linhas anteriores, como discursos conformam a subjetividade humana, como estes sujeitos são "criados" através de enunciados. Retomamos que o que é uma questão central para este estudo pode ser reconhecido nas ideias de Foucault. Ele sublinha que em seu trabalho, em sua temática de sua pesquisa, a figura central é o sujeito. De outra maneira, como os seres humanos tornam-se sujeitos, em relações de poder que são atravessadas pelos discursos; de que forma a subjetividade é então produzida pela exterioridade e objetiva o sujeito.

As práticas discursivas da Administração de Empresas tentam estabelecer que o trabalhador deve receber o discurso da verdade e tornar-se porta-voz desse discurso, o "embaixador da empresa". A lógica da função administrativa e de seus fundamentos é uma representação da coincidência entre o enunciador e o enunciado; da ligação do sujeito, subjetivado pelos discursos e objetivado em ação, com a sua própria verdade fabricada. As disciplinas que se entrelaçam aos discursos e usos equipam e reforçam, disponibilizam as formas de ação necessárias a reprodução do poder. 
Diante do contato com as práticas discursivas administrativas, pudemos formular algumas reflexões. A Administração de Empresas é a ciência da demonstração, pautada na coerção da realidade por uma dita eficiência; o seu principal método é o estudo de caso, e a atuação profissional dá-se por meio de ferramentas. É o que se faz produtivo da realidade ou o que se produz nela que se torna científico. Parece não haver discussão suficiente para uma mudança de fundamentos destes saberes em uso, só da atualização dos mesmos fundamentos em novos instrumentos; apenas as tecnologias se atualizam em novos vocabulários.

Não há discussão, nos registros aqui investigados, de um questionamento sobre o discurso de eficiência, de melhores práticas e da localização das organizações como construções historicamente produzidas, apenas como produtoras de determinações históricas. Não parece haver a possibilidade de desnaturalizar a empresa. A lógica administrativa propõe formatos, formas somente que se intercalam, mas que pretendem o mesmo, a mais econômica e lucrativa forma de trabalhar e de ser trabalhador: parece ser o cinismo da exploração na forma escolástica ou pedagógica. A administração parece estar pautada em uma duplicação da dominação como a profissão que é moldada ao moldar o trabalho. A disciplina administrativa parece ser o discurso científico que se cria nos usos, e que se faz no poder de exploração, ao trazer o carimbo de ciência-arte.

\section{Referências}

Bernardo, M. H. (2009). Trabalho duro, discurso flexível: uma análise das contradições do toyotismo a partir da vivência dos trabalhadores (1 $1^{\underline{a}}$ ed.). São Paulo: Expressão Popular.

Barros, S. P. (2010). A promoção de qualidade de vida para os trabalhadores: discurso, poder e disciplina. Dissertação de Mestrado. Instituto de Psicologia da Universidade de São Paulo, São Paulo.

Barros, S. P. (2015). Biopolítica, neoliberalismo e vulnerabilidade: os trabalhadores terceirizados na universidade pública. Tese de Doutorado. Instituto de Psicologia da Universidade de São Paulo, São Paulo.

Bertero, C. O., Caldas, M. P., \& Wood Jr., T. (1999). Produção científica em administração de empresas: provocações, insinuações e contribuições para um debate local. Revista de Administração Contemporânea, 3 (1), 147-178.

Deleuze, G. (2005). Foucault. São Paulo: Brasiliense.

Eribon, D. (1996). Michel Foucault e seus contemporâneos. Rio de Janeiro: Zahar.

Faria, J. H. (Org.) (2007). Análise crítica das teorias e práticas organizacionais. São Paulo: Atlas.

Farina, H. C. (2015). Qual a ética da empresa ética? Contradições na vivência de trabalhadores de grandes empresas contemporâneas. Dissertação de Mestrado. Instituto de Psicologia da Universidade de São Paulo, São Paulo.

Fayol, H. (1976). Administração industrial e geral (9aa ed.). São Paulo: Atlas.

Ford, C. M., \& Gioia, D. A. (Eds.) (1995). Creative action in organizations. Londres: Sage.

Foucault, M. (1999a). A ordem do discurso (5a ed.). São Paulo: Loyola.

Foucault, M. (1985a). História da sexualidade: a vontade de saber (vol. 1). Rio de Janeiro: Graal.

Foucault, M. (1985b). História da sexualidade: o cuidado de si (vol. 2). Rio de Janeiro: Graal.

Foucault, M. (1988). História da sexualidade: o cuidado de si (10ª ed., vol. 3). Rio de Janeiro: Graal.

Foucault, M. (1999b). Microfísica do poder. Rio de Janeiro: Graal.

Foucault, M. (2010b). O Sujeito e o poder. In P. Rabinow, \& H. Dreyfus (Orgs.), Michel Foucault. uma trajetória filosófica. Para além do estruturalismo e da hermenêutica. Rio de Janeiro: Forense Universitária.

Foucault, M. (2003). Vigiar e punir. Petrópolis, RJ: Vozes.

Gutting, G. (Org.) (2005). The Cambridge companion to Foucault (2aㅡ ed.). New York: Cambridge University Press.

Manzini-Covre, M. L. (1981). A formação e a ideologia do administrador de empresa. Petrópolis, RJ: Vozes. 
Maximiano, A. C. A. (1995). Introdução à administração. São Paulo: Atlas.

Mintzberg, H. (1995). Criando organizações eficazes. São Paulo: Atlas.

Motta, F. C. P. (1983). A questão da formação do administrador. Revista de Administração de Empresas, 23 (4), 53-55. doi: 10.1590/S0034-75901983000400005

Ohno, T. (1988). Toyota production system: beyond large scale production. Portland, Oregon: Productivity Press.

Oliveira, F. M. U. (2016). Perspectivas em exercício: uma investigação sobre a lógica administrativa e o engajamento subjetivo no trabalho. Dissertação de Mestrado. Instituto de Psicologia da Universidade de São Paulo, São Paulo.

Pereira, M. S. (2015). As concepções sobre saúde do trabalhador, as práticas profissionais e o contexto de atuação de psicólogos organizacionais. Tese de Doutorado. Instituto de Psicologia da Universidade de São Paulo, São Paulo.

Segnini, L. (1988). A liturgia do poder: trabalho e disciplina. São Paulo: EDUC.

Stecher, A. (2015). La empresa flexible como dispositivo de gobierno. Aportes de la analítica de la gubernamentalidad al estúdio de las subjetividades laborales em América Latina. Universitas Psychologica, 14 (5), 1779-1794.

Stoner, J. A. F., \& Freeman, R. E. (1995). Administração (5ํa ed.). Rio de Janeiro: Prentice Hall do Brasil.

Taylor, F. W. (1990). Princípios da administração científica (8⿳亠丷⿵冂⿰㐅㐅木 ed.). São Paulo: Atlas.

Womack, J., Jones, D. T., \& Roos, D. (1992). A máquina que mudou o mundo. Rio de Janeiro: Campus.

\section{Endereço para correspondência \\ flavia.muo@gmail.com}

Recebido em: 04/05/2016

Revisado em: 06/12/2016

Aprovado em: 06/12/2016 